\title{
ОТ КОНЦЕПЦИИ НАДЛЕЖАЩЕГО ГОСУДАРСТВЕННОГО УПРАВЛЕНИЯ К ПРАКТИКЕ АДМИНИСТРАТИВНОГО ПРАВОТВОРЧЕСТВА ФЕДЕРАЛЬНЫХ ОРГАНОВ ИСПОЛНИТЕЛЬНОЙ ВЛАСТИ
}

$\mathrm{K}$ аким должно быть государственное управление? Этот вопрос занимал мыслителей с античных времен, о чем свидетельствуют дошедшие до нас работы Платона и Аристотеля, но поиск идеала до сих пор актуален. В настоящее время государственное управление является предметом рассмотрения многих наук, в числе которых можно назвать политологию, правоведенье, науку государственного управления и др.

Прогрессивные мировые достижения в исследовании государственного управления необходимо учитывать при проведении административных реформ в каждом государстве, следует стремиться к реализации на практике признанного прогрессивной частью мирового сообщества идеалу надлежащего государственного управления («Good Governance»).

В настоящей статье основные начала современной концепции надлежащего государственного управления («Good Governance») будут рассмотрены с точки зрения их реализации в нормативном регулировании процесса разработки и принятия нормативных правовых актов (далее - НПА) федеральными органами исполнительной власти, поскольку как заметил Д.Н. Бахрах, государственное управление наряду с правоприменением осуществляет административное правотворчество (правоустановление) ${ }^{1}$. Проведение государством реформ различных видов государственного управления, различных отраслей законодательства на основе общих принципов позволит обеспечить системность реформ и их непротиворечивость.

В связи с этим, анализ принципов современной концепции "Good Governance» (надлежащего государственного управления), позволит выявить направления для усовершенствования административного правотворчества, то есть подготовки и издания НПА федеральными органами исполнительной власти как одной из возможных видов государственного управления.

\footnotetext{
Бахрах Д.Н., Россинский Б.В., Старилов Ю.Н. Административное право. - М., 2008. - С. 33.
}

Издание федеральными органами исполнительной власти качественных НПА, в рамках процедуры, обеспечивающей реализацию принципов надлежащего государственного управления («Good Governance»), должно рассматриваться как одно из необходимых условий эффективности механизма административноправового регулирования.

Термин «Good Governance» еще не получил общепринятого перевода. Представляется, что наиболее подходящим является перевод «Надлежащее государственное управление» (далее - НГУ), поскольку он более полно отражает содержание концепции, в отличие от, например, «качественного государственного управления» ${ }^{2}$ или «хорошего управления» ${ }^{3}$, и чаще всего используется в переводах международных документов, к которым присоединилась Российская Федерация, например, в Конвенции об уголовной ответственности за коррупцию (ЕTS № 173).

Вместе с тем, эффективность государственного управления является неотъемлемой частью концепции НГУ, реализующей предложенный О.В. Шмалий подход к пониманию эффективности исполнительной власти как системному взаимодействию двух составляющих - законности и результативности, который позволил обосновать понимание эффективности исполнительной власти как состояния ее организации и осуществления, обеспечивающего достижение правовыми средствами выраженных в праве целей ${ }^{4}$.

Кроме того, следует отметить, что в рамках дословного перевода термина «Good Governance» слово

\footnotetext{
2 Маслова Н.Р. Проблемы нормативно-правового обеспечения реализации Стратегии развития информационного общества в РФ на региональном уровне // Эволюция государственных и правовых институтов в условиях развития информационного общества / отв. ред. И.Л. Бачило. - М.: ИГП РАН, 2012. - С. 108-121.

Тихомиров Ю.А. Правовое государство: модели и реальность // Журнал российского права. - 2011. - № 12. - С. 5-20.

4 Шмалий О.В. Правовое обеспечение эффективности исполнительной власти: теоретико-методологические аспекты: дис. ... д-ра юрид. наук. - Ростов-н/Д, 2011. - С. 13.
} 
«государственное» на английском языке отсутствует, но в русской транскрипции оно необходимо, поскольку в концепции речь идет именно об управлении государством, причем не только об управленческой деятельности государственных органов, но и негосударственных акторов.

Концепция НГУ освещается в материалах международных организаций, таких как ООН и ОЭСР.

В рамках ОЭСР создана специальная организационная структура по координации теоритических разработок и практики проведения административных реформ - Комитет по публичному менеджменту ОЭСР.

Вместе с тем, принимая во внимание, что в деятельность ООН вовлечено большее количество государств, подходы ООН должны обладать сравнительно более универсальным характером, поэтому обратимся к ее разработкам.

Базовые характеристики НГУ согласно материалам Экономической и социальной комиссии ООН по Азии и Тихоокеанскому региону (ESCAP) включают участие, ориентированность на консенсус, подотчетность, транспарентность, быстрота реагирования, эффективность и квалифицированность, равенство, недискриминационность (инклюзивность) и верховенство [10].

Рассмотрим указанные характеристики НГУ, чтобы выявить какие из них уже реализованы, а какие, если это будет целесообразно, только предстоит учесть при реформировании правового регулирования разработки и принятия НПА.

В качестве одного из основных принципов НГУ $\mathrm{OOH}$ предлагает рассматривать участие в государственном управлении населения (мужчин и женщин), которое может быть непосредственным или опосредованным через легитимных представителей.

Вместе с тем, важно отметить, что участие через представителей не обязательно означает учет интересов всех, и особенно наиболее уязвимых и малочисленных групп населения, в процессе принятия решений. Главное, что требуется от государственных органов это то что, участие должно быть организовано и информационно обеспечено. Участие подразумевает наличие свободы ассоциаций и самовыражения, а также организованного гражданского общества.

При рассмотрении принципа участия в первую очередь следует отметить, что разработкой НПА занимаются, как правило, государственные служащие федеральных органов исполнительной власти, что безусловно является одной из форм участия граждан. Согласно ст. 4 Федерального закона от 27 июля 2004 г. № 79-Ф3 «О государственной гражданской службе Российской Федерации» одним из принципов государственной службы является равный доступ граждан, владеющих государственным языком РФ, к гражданской службе и равные условия ее прохождения независимо от пола, расы, национальности, происхождения, имущественного и должностного положения, места жительства, отношения к религии, убеждений, принадлежности к общественным объединениям, а также от других обстоятельств, не связанных с профессиональными и деловыми качествами гражданского служащего.

Затем, необходимо отметить, что в процессе дальнейшей подготовки и издания НПА федеральными органами исполнительной власти участие более широкого круга граждан и организаций (чем при собственно разработке проекта НПА) обеспечивается в рамках процедур общественной экспертизы проектов НПА и публичных обсуждений. Вместе с тем, следует отметить, что от государства зависит только организационная составляющая, а наибольшая доля ответственности ложится на представителей гражданского общества и групп интересов, их компетентности и активности.

Следующим принципом НГУ является верховенство закона, который является одним из общеправовых принципов. Этот принцип закреплен в Конституции РФ: в ст. 14 указано, что Конституция РФ и федеральные законы имеют верховенство на всей территории РФ.

Также следует отметить, что верховенство закона рассматривается в актах международного права (Парижской хартии для новой Европы от 21 ноября 1990 г.) как основа демократии.

Суть верховенство закона рассматривается и в правовой доктрине. Например, О.И. Короткова пишет, что «верховенство закона выражается в том, что главные, основополагающие общественные отношения во всех сферах общественной жизни регулируются законами, обеспечивая реальность прав и свобод граждан, их юридическую защищенность. Верховенство закона означает также его всеобщность, не оставляющую не урегулированных законом наиболее существенных областей жизни общества. Наконец, верховенство закона означает утверждение его господства, т.е. такого его положения, когда выраженные в нем начала и устои общества оставались бы непоколебимыми, а все субъекты общественной жизни без всякого исключения должны подчиняться его нормам»5.

Кроме того, заслуживает внимание содержание принципа верховенство закона, предложенное ООН. Генеральный секретарь $\mathrm{OOH}$ в одном из своих до-

Короткова О.И. Формирование правового государства и обеспечение верховенства закона // Государственная власть и местное самоуправление. - 2012. - № 5. - С. 3-12. 
кладов определил верховенство закона «как принцип государственного управления, согласно которому все лица, учреждения и структуры, государственные и частные, в том числе само государство, функционируют под действием законов, которые были публично приняты, в равной степени исполняются и независимо реализуются судебными органами и которые совместимы с международными нормами и стандартами в области прав человека. Для этого также необходимы меры, обеспечивающие соблюдение принципов примата права, равенства перед законом, ответственности перед законом, беспристрастного применения законов, разделения властей, участия в принятии решений, правовой определенности, недопущения произвола и процессуальной и правовой транспарентности» ${ }^{6}$.

В процессе подготовки и издания НПА федеральными органами исполнительной власти учтены оба аспекта принципа законности: во-первых, нормативно закреплена процедура подготовки и издания НПА постановлением Правительства РФ от 13 августа 1997 г. № 1009 «Об утверждении Правил подготовки нормативных правовых актов федеральных органов исполнительной власти и их государственной регистрации», а во-вторых, содержание НПА проходит проверку соответствия законодательству РФ в рамках правовой экспертизы юридической службы федерального органа исполнительной власти, а в случаях, когда НПА затрагивают права, свободы и обязанности человека и гражданина, устанавливают правовой статус организаций, имеют межведомственный характер, Минюст России проводит правовую экспертизу НПА при их регистрации (на практике возможны случаи проведения Минюстом России правовой экспертизы с указанием отсутствия необходимости государственной регистрации).

Транспарентность является одним из главных принципов НГУ и означает, что процедуры принятия и вступления в силу НПА соответствуют установленным правилам, в совокупности с тем, что информация о ходе разработки НПА находится в свободном и прямом доступе для тех, на кого эти акты распространяются. Информация должна быть достаточной и должна предоставляться в понятной форме и в доступных средствах массовой информации.

При издании НПА федеральными органами исполнительной власти транспарентность обеспечивается за счет размещения информации о разрабатываемых проектах НПА на официальном и на специальном

6 Доклад Генерального секретаря «Господство права и правосудие переходного периода в конфликтных и постконфликтных обществах» (S/2004/616)/ [Электр. pecypc] // URL: http://daccess-dds-ny.un.org/doc/UNDOC/GEN/N04/395/31/ PDF/N0439531.pdf?OpenElement. сайте regulation.gov.ru в соответствии с постановлением Правительства РФ от 25 августа 2012 г. № 851 «О порядке раскрытия федеральными органами исполнительной власти информации о подготовке проектов нормативных правовых актов и результатах их общественного обсуждения».

Опубликование изданных и зарегистрированных НПА федеральных органов исполнительной власти осуществляется в порядке, установленном Указом Президента РФ от 23 мая 1996 г. № 763 «О порядке опубликования и вступления в силу актов Президента Российской Федерации, Правительства Российской Федерации и нормативных правовых актов федеральных органов исполнительной власти» и постановлением Правительства РФ от 13 августа 1997 г. № 1009 «Об утверждении Правил подготовки нормативных правовых актов федеральных органов исполнительной власти и их государственной регистрации». Реализация принципа транспарентности затрагивает различия в «официальном опубликовании» и «официальном тексте» НПА, которое отмечает С.В. Бошно при анализе Указа Президента РФ от 23 мая 1996 г. № 763: «Систематическое и языковое толкование текста Указа приводит к выводу: выражения «официальное опубликование» и «официальный текст» не являются синонимами. В первом случае речь идет о процессуальной стороне правотворческого процесса, в котором с опубликованием связывается возможность вступления правового акта в юридическую силу. Именно об опубликовании идет речь в Конституции РФ. Выражение «официальный текст» означает, что он является точным, гарантированным от фальсификаций. Это очень важно для нормативных правовых актов, но не заменяет официального опубликования» ${ }^{7}$. Следует отметить, что указанное различие способно вызвать сложности при применении актов Президента РФ и актов Правительства РФ, в связи с тем, что распространение в электронном виде федеральным государственным унитарным предприятием «Научно-технический центр правовой информации «Система» Федеральной службы охраны РФ, а также органами государственной охраны официальных текстов актов Президента РФ и актов Правительства РФ не может рассматриваться как их опубликование. Для НПА федеральных органов государственной власти такой сложности не возникает, в связи с тем, что нормативными актами не предусмотрено их распространение в электронном виде, приравненном к их официальному опубликованию.

Бошно С.В. Развитие признаков нормативного правового акта в современной правотворческой практике // Журнал российского права. - 2004. - № 2. - С. 95-106. 
Следующим принципом НГУ является быстрота реагирования на существующие проблемы. В контексте НГУ быстрота реагирования на существующие проблемы означает осуществление действий и принятие решений, призванных служить интересам общества, в разумные сроки.

Принцип быстроты реагирования при издании НПА федеральными органами исполнительной власти не реализован. Даже при наличии сроков издания НПА федеральных органов исполнительной власти, установленных соответствующими поручениями Правительства РФ или Президента РФ, они не всегда соблюдаются. Нормативно не закреплена обязанность федеральных органов исполнительной власти быстро реагировать и урегулировать определенные общественные отношения путем издания НПА в связи с обращениями граждан.

Кроме того, реализация этого принципа затрагивает проблему издания актов федеральными органами исполнительной власти в инициативном порядке. Важно отметить, что некоторые исследователи не поддерживают возможность издания НПА в инициативном порядке. Например, М.В. Никифоров ${ }^{8}$ считает, что существование «инициативных» подзаконных НПА противоречит самой сути этих актов как подзаконных и служит безосновательной легализации и абсолютизации административного усмотрения. В этой связи, обращения граждан, об инициировании издания НПА вряд ли следует рассматривать как более весомое основание, чем соответствующая инициатива федерального органа исполнительной власти.

Вместе с тем, в целях реализации указанного принципа НГУ представляется целесообразным нормативно закрепить право федеральных органов исполнительной власти в сфере их компетенции в инициативном порядке издавать НПА, носящие процедурный характер и НПА, не предусматривающие возложение на граждан и организаций дополнительных обязанностей на граждан и организации.

К принципам НГУ ООН также относит необходимость ориентироваться на консенсус. Учет различных интересов и достижение максимально широкого консенсуса в обществе обеспечивает соответствие принимаемых решений интересам наибольшего количества членов общества. Вместе с тем, при принятии решений должна быть учтена долгосрочная перспектива, а также приняты во внимание необходимые меры для обеспечения достижения целей устойчивого развития.

Указанный принцип реализован в процедуре подготовки и издания федеральными органами исполни-

\footnotetext{
8 Никифоров М.В. Субъекты административного нормотворчества: монография. - Н.Новгород, 2012. - С. 37.
}

тельной власти НПА только в ограниченной мере - с точки зрения обязательности консенсуса заинтересованных федеральных органов исполнительной власти. Позиция граждан и организаций носит скорее факультативный характер, что обусловлено отсутствием институциональной организованности представителей граждан и организаций. Вместе с тем, отдельные достижения в ориентированности на консенсус реализованы при регулировании процедуры антикоррупционной экспертизы проектов НПА посредством установления обязательности результатов экспертизы в случаях, предусмотренных Федеральным законом от 17 июля 2009 г. № 172-Ф3 «Об антикоррупционной экспертизе нормативных правовых актов и проектов нормативных правовых актов»).

Равенство и недискриминационность (инклюзивность) как принцип НГУ в понимании Экономической и социальной комиссии ООН по Азии и Тихоокеанскому региону (ESCAP) связано с благосостоянием. Рассматривая равенство и недискриминационность (инклюзивность) ESCAP на своем официальном сайте указывает, что благосостояние общества зависит от уверенности его членов в том, что они участвуют в распределении благ, и не чувствуют себя отстраненными от основных происходящих процессов. Все члены общества, и в особенности наиболее уязвимые, должны иметь возможность улучшить или поддерживать на постоянном уровне свое благосостояние 9 .

Согласно указанной трактовке этот принцип напрямую отсутствует в процедуре подготовки и издания федеральными органами исполнительной власти НПА. В буквальном значении равенство и недискриминационность закреплены в ст. 6 и 19 Конституции РФ и их соблюдение должно проверяться в рамках правовой экспертизы проектов НПА.

Следующим принципом НГУ является принцип эффективности. Эффективность в данном случае подразумевает, что государственное управление может быть признано надлежащим, если административные процедуры и результаты деятельности государственных органов соответствуют интересам общества, а, имеющиеся в распоряжении государственных органов, ресурсы используются наилучшим образом. Принцип эффективности в контексте концепции НГУ включает также использование ресурсов согласно концепции устойчивого развития и защиту окружающей среды.

Эффективность НПА должна быть оценена при

\footnotetext{
9 Материалы Экономической и социальной комиссии $\mathrm{OOH}$ по Азии и Тихоокеанскому региону The United Nations Economic and Social Commission for Asia and the Pacific (ESCAP) [Электр. pecypc] // URL: http://www.unescap.org/ $\mathrm{pdd} / \mathrm{prs} /$ projectactivities/ongoing/gg/governance.asp
} 
проведении оценки регулирующего воздействия. Вместе с тем, не смотря на развитие нормативного- правового и методического обеспечения процедуры оценки регулирующего воздействия критерии эффективности НПА нормативно не закреплены. Вместе с тем, в науке административного права этот вопрос стал предметом изучения. Например, А.А. Разуваев рассматривает в рамках исследования экспертизы как средства повышения эффективности правореализации эффективность норм права как их результативность, т.е. способность достигать поставленных целей, позитивно влиять на общественные отношения и, на поведение субъектов правового регулирования ${ }^{10}$. Е.В. Журкина считает возможным определить понятие «эффективность законодательства» как совокупность признаков, характеризующих "формальное» совершенство входящих в его систему нормативных правовых актов, и свойств, способствующих наиболее оптимальному регулированию общественных отношений в соответствии с поставленными нормотворцем целями ${ }^{11}$. Предложенное Е.В. Журкиной определение понятия «эффективность законодательства» представляет интерес для теоретических разработок, оно не является применимым на практике, поскольку далеко не всегда цели нормотворца бывают зафиксированы или достаточно конкретизированы для проведения последующей формальной оценки достигнутых результатов.

Подотчетность является ключевым принципом НГУ. Подотчетность достаточно широко трактуемый принцип, поскольку его содержание касается не только государственных органов, но также и частных предприятий, организаций гражданского общества, которые должны быть подотчетны лицам, интересы которых они представляют. При этом, принцип подотчетности не может быть реализован без принципов транспарентности и верховенства закона.

Принцип подотчетности в процедуре издания федеральными органами исполнительной власти НПА не реализован.

Указанные принципы составляют основу концепции НГУ, которая предлагает нам идеальную модель государственного управления, которую сложно полностью реализовать на практике. Реализация отдельных принципов НГУ частично обеспечивается в нормативных правовых актах, регламентирующих правила подготовки нормативных правовых актов федеральных органов исполнительной власти и их государственной регистрации. Вместе с тем, к полной реализации идеала НГУ необходимо продолжать стремиться.

Реализация принципов НГУ должна контролироваться в рамках специальных процедур, в частности при проведении различного рода экспертиз как проектов нормативных правовых актов федеральных органов исполнительной власти на стадии их разработки, так и уже вступивших в силу проектов нормативных правовых актов федеральных органов исполнительной власти.

Еще не реализованные принципы должны служить ориентиром при подготовке проектов нормативных правовых актов федеральных органов исполнительной власти для разработчиков проектов нормативных правовых актов и должны быть учтены при совершенствовании процедуры подготовки и принятия федеральными органами исполнительной власти проектов нормативных правовых актов.

\section{Библиографический список:}

1. Бахрах Д.Н., Россинский Б.В., Старилов Ю.Н. Административное право. - М., 2008. - С. 815.

2. Маслова Н.Р. Проблемы нормативно-правового обеспечения реализации Стратегии развития информационного общества в РФ на региональном уровне Эволюция государственных и правовых институтов в условиях развития информационного общества / отв. ред. И.Л. Бачило. - М.: ИГП РАН, 2012. - С. 108-121.

3. Никифоров М.В. Субъекты административного нормотворчества: монография. - Н.Новгород, 2012. - С. 208.

4. Журкина Е.В. Правовая экспертиза нормативного правового акта как средство повышения эффективности законодательства: дис. ... канд. юрид. наук. - М., 2009.

5. Разуваев А.А. Экспертиза как средство повышения эффективности процесса правореализации: вопросы теории и практики: дис. ... канд. юрид. наук. - Саратов, 2006.

6. Шмалий О.В. Правовое обеспечение эффективности исполнительной власти: теоретико-методологические аспекты: дис. ... д-ра юрид. наук. - Ростов-н/Дону, 2011.

10 Разуваев А.А. Экспертиза как средство повышения эффективности процесса правореализации: вопросы теории и практики: дис. ... канд. юрид. наук. - Саратов, 2006. - С. 110-111.

11 Журкина Е.В. Правовая экспертиза нормативного правового акта как средство повышения эффективности законодательства: дис. ... канд. юрид. наук. - М., 2009. - С. 9. 
Административное и муниципальное право 11 (71) • 2013

7. Бошно С.В. Развитие признаков нормативного правового акта в современной правотворческой практике // Журнал российского права. - 2004. - № 2. - С. 95-106.

8. Тихомиров Ю.А. Правовое государство: модели и реальность // Журнал российского права. - 2011. № 12 . - С. 5-20.

9. Короткова О.И. Формирование правового государства и обеспечение верховенства закона // Государственная власть и местное самоуправление. - 2012. - № 5. - С. 3-12.

10. Материалы Экономической и социальной комиссии ООН по Азии и Тихоокеанскому региону The United Nations Economic and Social Commission for Asia and the Pacific (ESCAP) [Электронный pecypc] // URL: http:// www.unescap.org/pdd/prs/projectactivities/ongoing/gg/governance.asp

11. Доклад Генерального секретаря «Господство права и правосудие переходного периода в конфликтных и постконфликтных обществах» (S/2004/616)/ [Электронный ресурс] // URL: http://daccess-dds-ny.un.org/doc/ UNDOC/GEN/N04/395/31/PDF/N0439531.pdf?OpenElement.

\section{References (transliteration):}

1. Bakhrakh D.N., Rossinskii B.V., Starilov Yu.N. Administrativnoe pravo. - M., 2008. - S. 815.

2. Maslova N.R. Problemy normativno-pravovogo obespecheniya realizatsii Strategii razvitiya informatsionnogo obshchestva v RF na regional'nom urovne Evolyutsiya gosudarstvennykh i pravovykh institutov $v$ usloviyakh razvitiya informatsionnogo obshchestva / otv. red. I.L. Bachilo. - M.: IGP RAN, 2012. - C. 108-121.

3. Nikiforov M.V. Sub"ekty administrativnogo normotvorchestva: monografiya. - N.Novgorod, 2012. - S. 208.

4. Zhurkina E.V. Pravovaya ekspertiza normativnogo pravovogo akta kak sredstvo povysheniya effektivnosti zakonodatel'stva: dis. ... kand. yurid. nauk. - M. 2009.

5. Razuvaev A.A. Ekspertiza kak sredstvo povysheniya effektivnosti protsessa pravorealizatsii: voprosy teorii i praktiki: dis. ... kand. yurid. nauk. - Saratov, 2006.

6. Shmalii O.V. Pravovoe obespechenie effektivnosti ispolnitel'noi vlasti: teoretiko-metodologicheskie aspekty: dis. ... d-ra yurid. nauk. - Rostov-n/Donu, 2011.

7. Boshno S.V. Razvitie priznakov normativnogo pravovogo akta v sovremennoi pravotvorcheskoi praktike // Zhurnal rossiiskogo prava. - 2004. - № 2. - S. 95-106.

8. Tikhomirov Yu.A. Pravovoe gosudarstvo: modeli i real’nost' // Zhurnal rossiiskogo prava. - 2011. - № 12. S. 5-20.

9. Korotkova O.I. Formirovanie pravovogo gosudarstva i obespechenie verkhovenstva zakona // Gosudarstvennaya vlast' i mestnoe samoupravlenie. - 2012. - № 5. - S. 3-12.

10. Materialy Ekonomicheskoi i sotsial'noi komissii OON po Azii i Tikhookeanskomu regionu The United Nations Economic and Social Commission for Asia and the Pacific (ESCAP) [Elektronnyi resurs] // URL: http://www.unescap.org/ $\mathrm{pdd} / \mathrm{prs} /$ projectactivities/ongoing/gg/governance.asp

11. Doklad General'nogo sekretarya «Gospodstvo prava i pravosudie perekhodnogo perioda v konfliktnykh i postkonfliktnykh obshchestvakh»(S/2004/616)/ [Elektronnyi resurs] // URL: http://daccess-dds-ny.un.org/doc/UNDOC/ GEN/N04/395/31/PDF/N0439531.pdf?OpenElement. 